generate a larger voltage. Another layer with a smaller bandgap is used to harvest the lower-energy photons. The layers are connected in series so that the voltages can be added in much the same way that batteries are connected in series to attain a higher voltage.

This year the vast majority of solar cells being manufactured will be made of crystalline silicon ${ }^{1}$. As the prospects for reducing their cost radically are low, many companies are racing to develop alternatives - mostly inorganic thinfilm solar cells based on amorphous silicon, CdTe and $\mathrm{Cu}\left(\operatorname{In}_{x} \mathrm{Ga}_{1-x}\right) \mathrm{Se}_{2}$. But all of these material systems have some drawbacks. It is hard to make amorphous silicon cells cost-effective because these films typically have to be deposited at an excruciatingly slow rate of a few ångströms per second. Films of CdTe and $\mathrm{Cu}\left(\mathrm{In}_{x} \mathrm{Ga}_{1-x}\right) \mathrm{Se}_{2}$ can be deposited faster, but simple calculations show that if all of the world's known reserves of tellurium and indium were used to make solar cells, one could only generate about $0.16 \mathrm{TW}$ of power. More of these elements will surely be found, but it remains unclear whether these semiconductors will be one of the chief players in solving the world's energy problem. The limitations of these technologies may leave the door open for polymer solar cells to lead the market in 10 to 15 years and provide the world with several terawatts or more of clean electricity. The advance reported in this issue is an important step towards realizing this dream.

Michael D. McGehee is in the Department of Materials Science and Engineering at Stanford University, 476 Lomita Mall, Stanford, California 94305-4045, USA.

e-mail:mmcgehee@stanford.edu

\section{References}

1. Ginley, D. S., Green, M. A. \& Collins, R. MRS Bull. 33, 355 (2008).

2. Mayer, A. C., Scully, S. R., Hardin, B. E., Rowell, M. W. \& McGehee, M. D. Mater. Today 10, 28-33 (2007).

Park, S. H. et al. Nature Photon. 3, 297-303 (2009).

4. Blom, P. W. M., Mihailetchi, V. D., Koster, L. J. A. \& Markov, D. E. Adv. Mater. 19, 1551-1566 (2007).

Mihailetchi, V. D., Wildeman, J. \& Blom, P. W. M. Phys. Rev. Lett. 94, 126602 (2005).

6. Scharber, M. C. et al. Adv. Mater. 18, 789-794 (2006)

7. Dennler, G. et al. Adv. Mater. 20, 579 (2008).

\title{
Ultraviolet-emitting gallium nitride fractals
}

Although fabrication of complex fractal structures remains immensely challenging in the lab, it is commonplace in nature: snowflakes, lightning and the shell of the nautilus sea creature all show fractal patterns. Now, researchers from the University of Tokyo in Japan have succeeded in fabricating gallium nitride (GaN) fractal nanostructures that emit ultraviolet light at room temperature (Appl. Phys. Express 2, 031004; 2009). The nanostructures made by Shunsuke Yamazaki and his colleagues resemble dendrites - the tree-like extensions found on nerve cells.

The GaN fractals were grown at room temperature on a sapphire substrate by photochemical vapour deposition in a reaction chamber containing trimethylgallium and ammonia gases. The researchers used a fifth harmonic Q-switched Nd:YAG laser $(\lambda=213 \mathrm{~nm})$ to initiate photodissociation and split

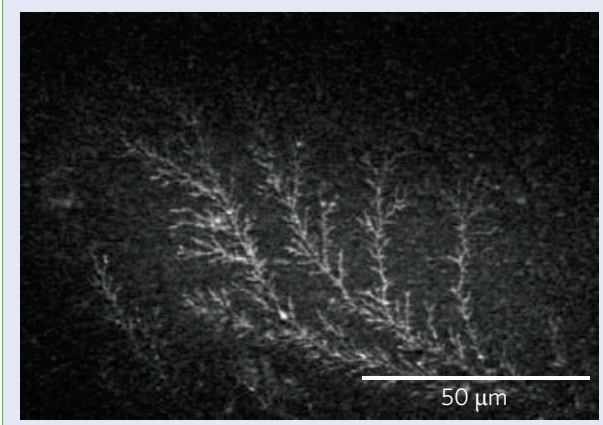

the trimethylgallium and ammonia into their constituents, triggering the growth of gallium nitride.

Fractals have a self-similar structure in that they are characterized by the repetition of similar patterns at everdiminishing scales. They occur naturally all around us, famous examples being snowflakes, dielectric breakdown (lightning), stalagmites and stalactites, sea urchins, starfish, broccoli, ferns and veins on some leaves. Even mountain ranges and shorelines can be loosely fractal

Yamazaki's dendritic fractals were formed by diffusion: that is, the particles experienced Brownian (random) motion until they touched a solid structure and solidified onto it. Reiteration of the process results in the fabrication of the fractals. Dendritic fractals are known to have a fractal dimension - a 'packing' parameter describing how much space the fractal fills - of about 1.7. And, indeed, scanning electron microscopy images of the GaN nanostructures gave a similar value, indicating their dendritic fractal character.

Photoluminescence spectra from the dendritic GaN fractals revealed peaks confirming the high quality of the GaN crystalline structure and a quantum confinement effect. The latter occurs when materials have features comparable in size to the electronic wavefunction, in this case indicating the ultra-fine fractal structure of the GaN.

Structures with nano-sized features often offer unique optical and electronic properties that are very different from those of bulk materials. This latest research not only provides new avenues for fabrication of nanostructures, but is yet another example of nature's endless inspiration to science.

\section{DAVID PILE}

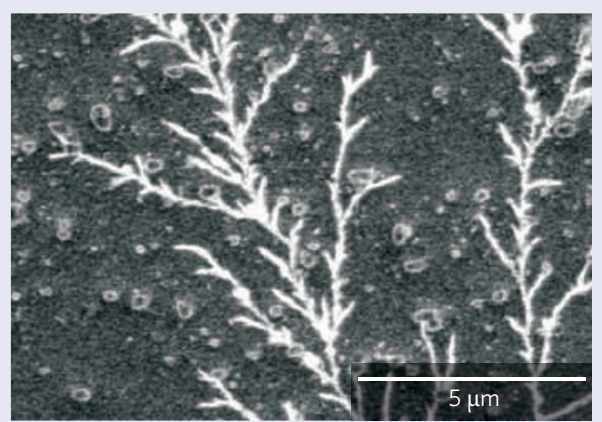

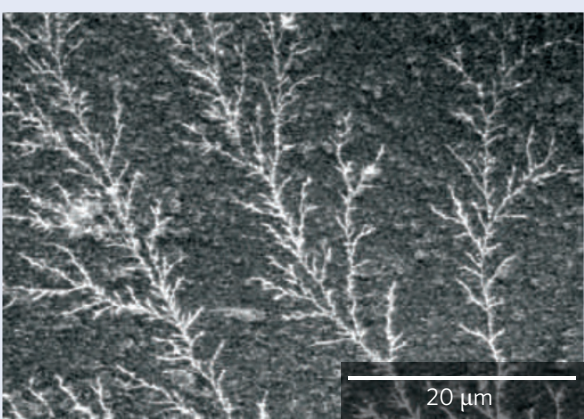

